\title{
A Study to Assess the Effectiveness of Structured Teaching Program on Knowledge Regarding Prevention of Infection among the Staff Nurses Working in Hemodialysis unit in Selected Hospitals in Chhattisgarh state, India
}

\author{
Lisa Louis Philip \\ College of Nursing, Apollo Hospital, Bilaspur, Chhattisgarh, India
}

\begin{abstract}
The effectiveness of structured teaching program was assessed based on the knowledge of staff nurses working in the hemodialysis unit regarding the prevention of infection. To compare the knowledge between control and experimental group used pretest and post test with the help of demographic variables and their association. Research approach used for the study was experimental approach \& quasi experimental research design. The non probability purposive sampling technique was used and the statistical method applied for the study. The study was conducted in the selected hospital in Chhattisgarh state, India.
\end{abstract}

Keywords: structured teaching program (STP), Nurses, hemodialysis, demographic variables, experimental, control, pilot study, pre test and post test

\section{Introduction}

Haemodialysis is the most common method used to treat advanced and permanent kidney failure. Since the 1960s, when hemodialysis first became a practical treatment for kidney failure, effective measures are taken to make the procedure to maximize its effect and minimize side effects.

\section{Infection prevention in hemodialysis unit}

The centres for disease Control and Prevention (CDC) in April 2001 released recommendations for preventing transmission of infections among Chronic Hemodialysis Patients, which specifically addressed the many opportunities that exist in the dialysis setting for the spread of infection. Professionals in the dialysis community have largely accepted the comprehensive document for use especially since there is no Canadian equivalent.

In 2002, a CDC communication to CMS suggested that reentry into single-use parental medication vials, when performed on a limited basis and under strict conditions in hemodialysis settings, likely would result in low risk for bacterial infection. However, the 2002 communication did not address risks for blood borne viral infections (e.g., HCV and hepatitis B virus infection).Epidemiological surveys have shown that despite the elimination of post transfusion $\mathrm{HCV}$ remains high among dialysis patients in the developed world.

The department of Human Services in 2004 conducted a review of kidney dialysis services across Victoria, this review focused primarily on service delivery.

Shahn Cullum Queensland Nephrology Nursing Network (QNNN) in September 2006, an infection control survey was undertaken by to identify current practices in relation to the management of patients with muti resistant organisms
(MRO) and blood borne viruses (BBV). Edren, the website of the renal unit at the Royal Infirmary of Edinburgh, Scotland released protocol for infection control precautions should be the same for all patients in hemodialysis unit.

Matthew J arduino "preventing Infections in patients Undergoing Hemodialysis" states that infections continue to be major cause of morbidity and mortality in patients with end-stage renal disease. S. Young in "implementing contact precautions in community dialysis units for closer-to-home care" reports that the initiative assessed barriers and facilitators to: implementing Contact Precautions; developing practice standards for nurses and renal technicians to enact contact precautions care and providing staff and patient education essential to implementing these standards.

Nurses' knowledge- infection prevention in hemodialysis unit

A comparative study was done to assess Nurses ${ }^{\text {ec }}$ knowledge and practice in hemodialysis units the comparison was between nurses in units with high low prevalence of hepatitis $\mathrm{C}$ virus infection.In conclusion, the HCV infection in high prevalence units is probably related to poor application of standard health precautions and that isolation does not prevent spread of the disease inside HD units.

A cross-sectional study on November 2007 was made in 32 hemodialysis units in the Nile delta, Egypt to evaluate knowledge and practices towards risk of HIV infection by 317 health care workers. Exposure to needle-stick injury was reported by $48.6 \%$ in the previous year. Crucani.T.Mannies in April 2003 conducted a descriptive study aims to evaluate occupational faced by nurses working in dialysis units and nephrology services. 


\section{International Journal of Science and Research (IJSR) \\ ISSN (Online): 2319-7064 \\ Index Copernicus Value (2013): 6.14 | Impact Factor (2014): 5.611}

Margaret Higgins in June 2008 conducted a study on nurse $\mathrm{s}$ knowledge and practice of vascular access infection control in haemodialysis patients states that although $92 \%$ of respondents reported that policies had been developed by their units and $47 \%$ had received infection control education in the previous year, knowledge and adherence to best practice demonstrated significant scope for improvement.

\section{Objectives of the study}

1) To assess the pretest and post knowledge of experimental and control group regarding prevention of infection among staff nurses working in hemodialysis.

2) To assess the effectiveness of structured programme regarding the prevention of infection among the staff nurses working in hemodialysis unit in experimental group.

3) To compare the pretest and post test knowledge of experimental and control group.

4) Find out the association between knowledge with selected demographical variables

\section{Need for the study}

Jane seden et al; (2002) Hospital infections can be spread between all hospital staff and visitors. Infection must account for every contingency involving possible bacterial transmission, no nursing personal must have every protection at the ready. Ghazi, Saleh, and Badadweh 2008 stated that end stage renal failure is a critical stage and the only treatment is dialysis. There has been increase in numbers of hemodialysis patient every year. This increases the workload of the hemodialysis nurses as nursing accounts for $80 \%$ of the direct care in providing care fulfilling their needs. Diabetes mellitus was the most common etiology of renal failure, followed by hypertension, urinary tract infection, and congenital malformation.

Association of Professional in infection control (APIC) in 2010 guide to elimination of infection in hemodialysis unit reports that hemodialysis (HD) patients are uniquely vulnerable to the development of healthcare associated infections because of multiple factors including exposure to invasive devices, immunosuppersion, the lack of physical barriers between patients in the outpatient hemodialysis environment and frequent contact with healthcare workers during procedures and care.

\section{Methods and Materials}

In this study two types of variables are used they are (i) Independent variable (ii) Dependent variable. Independent variables refer to the structure teaching program regarding knowledge of staff nurses regarding infection prevention in hemodialysis unit whereas dependent variable gaining of knowledge among the staff nurses regarding infection prevention in hemodialysis unit. Selected hospitals of Chattisgarh state namely,(i) Modern medical institute, Raipur (ii) Escorts hospital ,Raipur (iii) Apollo hospital, Bilaspur (iv) Ram Krishna hospital, Bhilai, were the selected sites and the data collection had been done here. According to Polit and Hungler Setting is the physical location \& condition in which data collection takes place in a study.

\section{Population, Sample, sample size and sample technique}

Staff nurses working in hemodialysis unit in the selected site had been noticed as a sample in the total population and there were 60 staff nurses included in the sample size, and therefore 30 for experimental group and 30 for control group. Non probability purposive sampling was used to select subjects from the target population.

Criteria for sample selection:

Inclusion criteria are characteristics that each sample element must possess to be included in the sample, these are all (i) Registered nurses (ii) Nurses who are willing to participate in the study (iii) Nurses who are available at the time of data collection and (iv) Nurses working in hemodialysis unit whereas exclusion criteria having following elements, (i) Nurses on leave (ii) Nurses on night shift (iii) Newly posted staff (iv) Ward in charges and supervisors.

\section{Selection and Developmental of Tools:}

Data collection instrument used was ,Structured questionnaire $^{e e}$ and the data collection method done through structured questionnaire.

\section{Description of tools:}

1) Socio-demographic Performa: This section consists of 9 question which deals with socio-demographic variables like age, gender, marital status, professional qualification, working experience, monthly income, hospital setting, family type and any relatives undergoing hemodialysis.

2) Structured knowledge questionnaire: structured questionnaire was prepared to assess the effectiveness of structured teaching program regarding infection prevention in hemodialysis unit. The total number of question is 24 and divided into 5 areas, (a) Infection control practices (b) equipment cleaning and disinfection (c) exterior cleaning and disinfection of hemodialysis machine (d) patient precaution and screening. All are closed ended question. The items were multiple choice types one correct answer each carrying one score and zero for wrong answer with the total aggregate of 24 scores. There would be scoring level for knowledge, inadequate knowledge 0-8 (33\%), Moderate knowledge: 9-16 (34-66\%) and adequate knowledge: 17-24 (67$100 \%)$.

3) Structured teaching programme (STP) on prevention of infection in hemodialysis unit: The STP was developed according to the literature review, objectives, sample size and experts opinion and the content of STP are as follows (a) Introduction, (b) infection control practices (c)personal protective equipments (d) environmental cleaning and disinfection (e)exterior cleaning and infection of hemodialysis machine (f) interior cleaning and disinfection of hemodialysis machine and (g) patient precautions and screening.

Content Validity: The content validity of the instrument was assessed by obtaining from experts in the different fields of nursing and medicine. Appropriate modification was made accordingly and the tool was finalized by expert's 


\section{International Journal of Science and Research (IJSR) ISSN (Online): 2319-7064 \\ Index Copernicus Value (2013): 6.14 | Impact Factor (2014): 5.611}

suggestion and the final copy of the tools was prepared for the present study.

Reliability: The reliability of the measuring instrument is a major criterion for assessing the quality and adequacy. Knowledge score reliability was assessed using test retest method and its correlation coefficient values are 0.83 . This correlation coefficient is very high and it is good tool for assessing the effectiveness structured teaching programme reagarding infection prevention in hemodialysis unit.

Pilot Study: Pilot study is a small scale version or trial run of the major study to assess the feasibility in conducting the main study. Pilot study was undertaken for which a formal permission was obtained from the hospital administrator Chaitanya hospital Sagar, Madhya Pradesh. The researcher taken first the pre test and then administered STP to the experimental group and then after seven days post test was taken from experimental as well as in the control group with each person.

Data Collection procedure: Treece stated that instrument in a research should ask for as possible be a vehicle that would be the best obtaining data for drawing conclusion pertinent to the study. The procedure as (a) a formal written permission was taken from the hospital administrators of selected hospital, (b) consent was taken from the staff nurse working hemodialysis unit was taken (c) Nursese information kept confidential and used for research purpose (d)the investigator collected data from the selected hospitals and (e) investigator had taken pre test first of both experimental and control group \& then administered STP only to the experimental group and then after seven days the post test was taken from both the groups.

Hypothesis formulated for the study:

H1: There is a significant difference between the pretest and post test of experimental and control group regarding the prevention of infection among the staff nurses working in haemodialysis unit.

$\mathrm{H} 2$ : there is a significant association between the selected demographical and knowledge regarding the prevention of infection among the staff nurses working in hemodialysis unit.

H0: There is no significant difference between the pretest and post of experimental and control group regarding the prevention of infection among the staff nurses working in hemodialysis unit.

\section{Results}

\section{Analysis and interpretation}

Polit and Hungler (1999) described analysis as " a process of organizing and synthesizing data such a way that research question can be answered and hypothesis tested". Analysis and interpretation of data are based on the objectives and hypotheses of the study.

(i) Organization of findings- The data collected was tabulated and organized.

Section I- distribution of study subjects according to the socio demographic variables using frequency and percentage, among experimental $67 \%$ were female and $33 \%$ male where as in control group 57\% were female and $43 \%$ were male. In professional qualification $50 \%$ of staff were having GNM degree, BSc degree in experimental group, where as $36.6 \%$ of staff nurses were having GNM degree $16.7 \%$ of staff nurses were having Post basic degree $40.3 \%$ of staff nurses were having B.Sc degree, $3.3 \%$ of staff nurses is M.Sc degree.

Pie diagram showing family relatives undergoing hemodialysis in experimental group and control group depicts that $10 \%$ of staff nurses whose family members were undergoing hemodialysis, $90 \%$ of staff nurses whose family relatives were not undergoing hemodialysis in experimental group where as $6.7 \%$ of staff nurses whose family members were undergoing hemodialysis and $93.3 \%$ of staff nurses whose family relatives were not undergoing hemodialysis in control group.

(Figure 2.1) experimental group, staff nurses, pretest level of knowledge. In general $20.0 \%$ of them are having poor knowledge and $66.7 \%$ of them having average knowledge and $13.3 \%$ of them are having good knowledge whereas control group, staff nurses, pretest level of knowledge. In general $16.7 \%$ of them are having poor knowledge and $76.7 \%$ of them having average and $6.6 \%$ of them are having good knowledge.

Fig (2.2), experimental group, staff nurses, post test level of knowledge. In general none of them are having poor knowledge, $23.3 \%$ of them having average knowledge and $77.7 \%$ of them are having good knowledge, but in control group, staff nurses, post test level of knowledge. In general $13.3 \%$ of them are having poor knowledge and $80.0 \%$ of them having average knowledge and $6.7 \%$ of them are having good knowledge.

\section{(ii) Statistical Methods}

Section II-Comparison of pretest and post test scores to determine the effective of structure teaching program in table 1.1, in all aspects, staff nurses improved their knowledge after the administration of STP. Considering introduction aspect, in pre test, they scored only 2.40 , after STP they have scored 3.43 , so the difference is 1.03 . The difference between pre and post test knowledge score is large and statistically significant.

Considering infection practices, in pre test, they scored only 3.07, after STP they have scored 5.89, so the difference is 2.82 and it also statistically significant. Considering equipment cleaning and disinfection, in pretest, they scored only 3.20, after STP they scored 4.94, so the difference is 1.74 and it also significant. Consider exterior cleaning and disinfection of hemodialysis machine in pre test they scored only 1.53 , after STP they scored 3.33 so the difference 1.8 .

Patient and precaution and screening in pre test, they scored only 1.27 , after STP they scored 2.43 , so the difference is 1.16. The difference between pre and post test knowledge score is large and it is significant. Considering overall knowledge score, in pre test, they scored only 11.47 , after STP they scored 20.02, so the difference is 8.55 . The difference between pre and post test knowledge score is 


\section{International Journal of Science and Research (IJSR) \\ ISSN (Online): 2319-7064 \\ Index Copernicus Value (2013): 6.14 | Impact Factor (2014): 5.611}

large and it is significant. Statistical significance was calculated by using students paired ,t"e test.

On the contrary the comparison of knowledge score between experiment and control, in the pretest there is no difference between experiment and control group the mean value of pretest score which was calculated using unpaired test is $\mathrm{t}=$ $0.50 \mathrm{P}=0.61 \mathrm{df}=58$, in the post test there is a significant difference between experiment and control group. It was analyzed using unpaired t-test is $\mathrm{t}=6.27 \mathrm{P}=0.001 \mathrm{df}=58$

In experiment group, there is a significant difference between pretest and post test value of $\mathrm{t}=19.69 \mathrm{P}=0.001$. In control group, there is a no significant difference between difference between pretest and post knowledge score and value of $\mathrm{t}=0.69 \mathrm{P}=0.51$ it was analyzed using paired t-test.
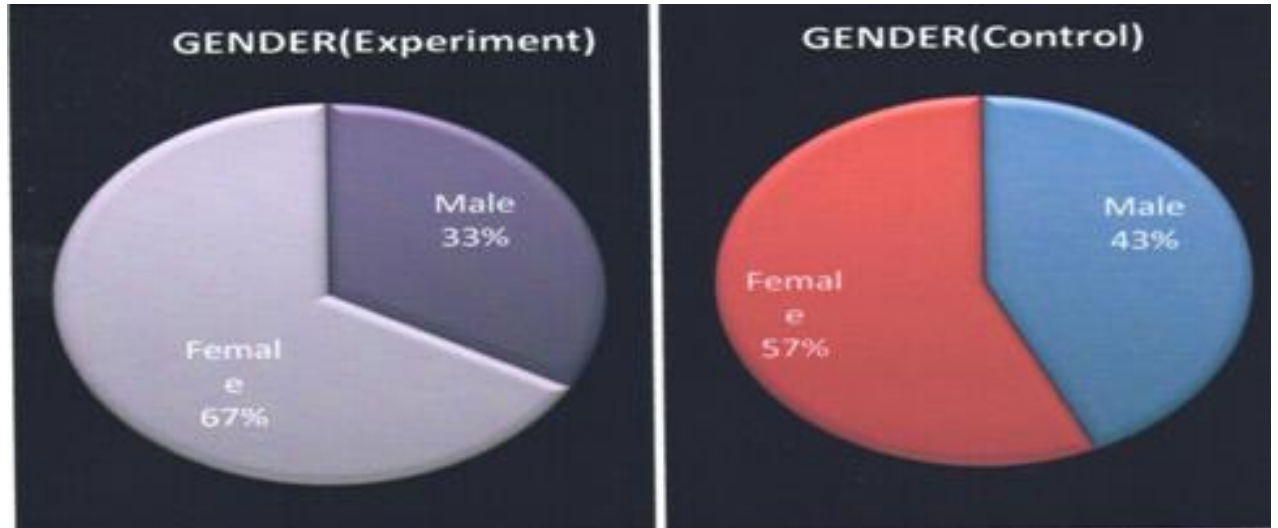

Figure 1.1: Percentage of subjects Pie diagram showing according to gender in experimental group and control group.

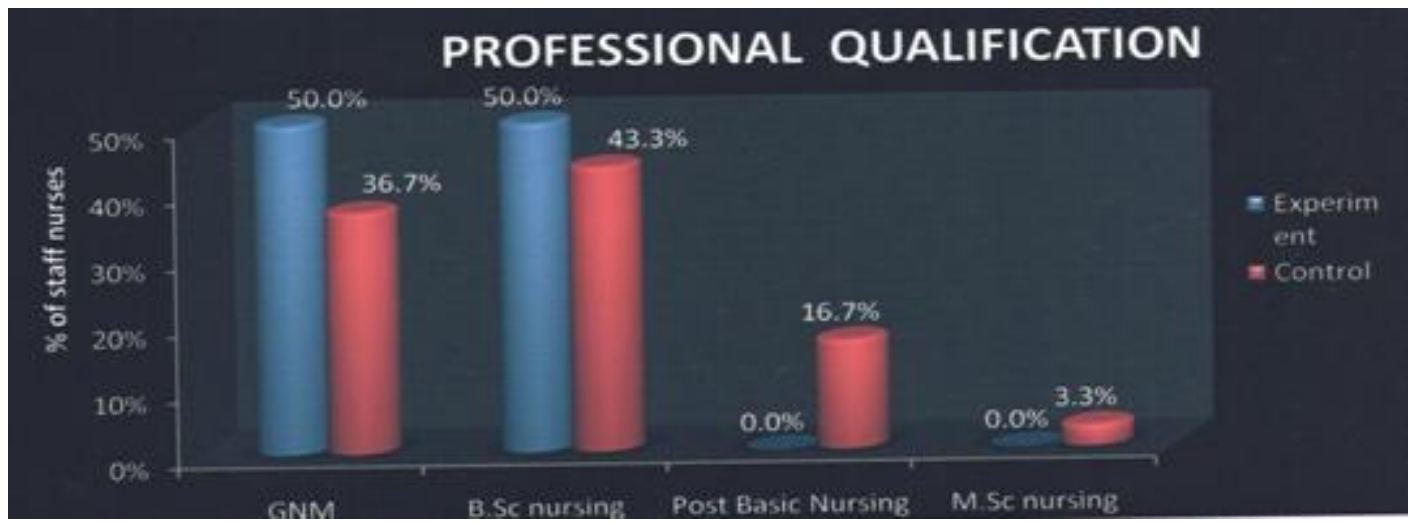

Figure 1.2: Percentage of subjects cylindrical diagram showing to professional qualification in experimental group and control group

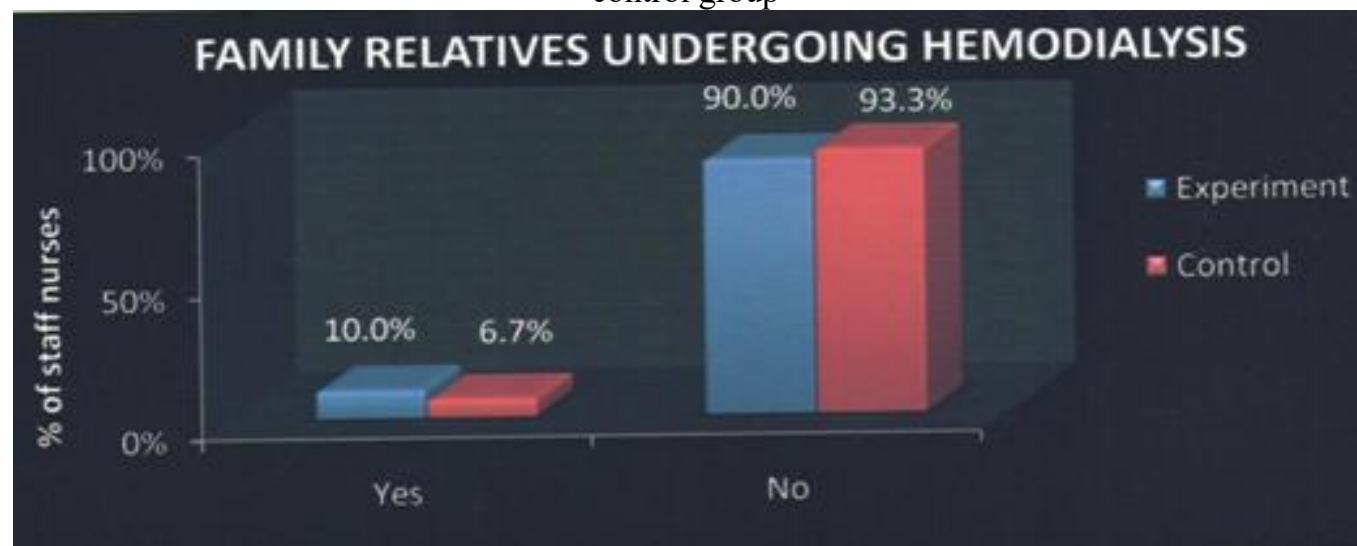

Figure 1.3: Percentages of subjects Pie diagram showing according to family members undergoing hemodialysis in experimental group and control group 


\section{International Journal of Science and Research (IJSR)}

ISSN (Online): 2319-7064

Index Copernicus Value (2013): 6.14 | Impact Factor (2014): 5.611

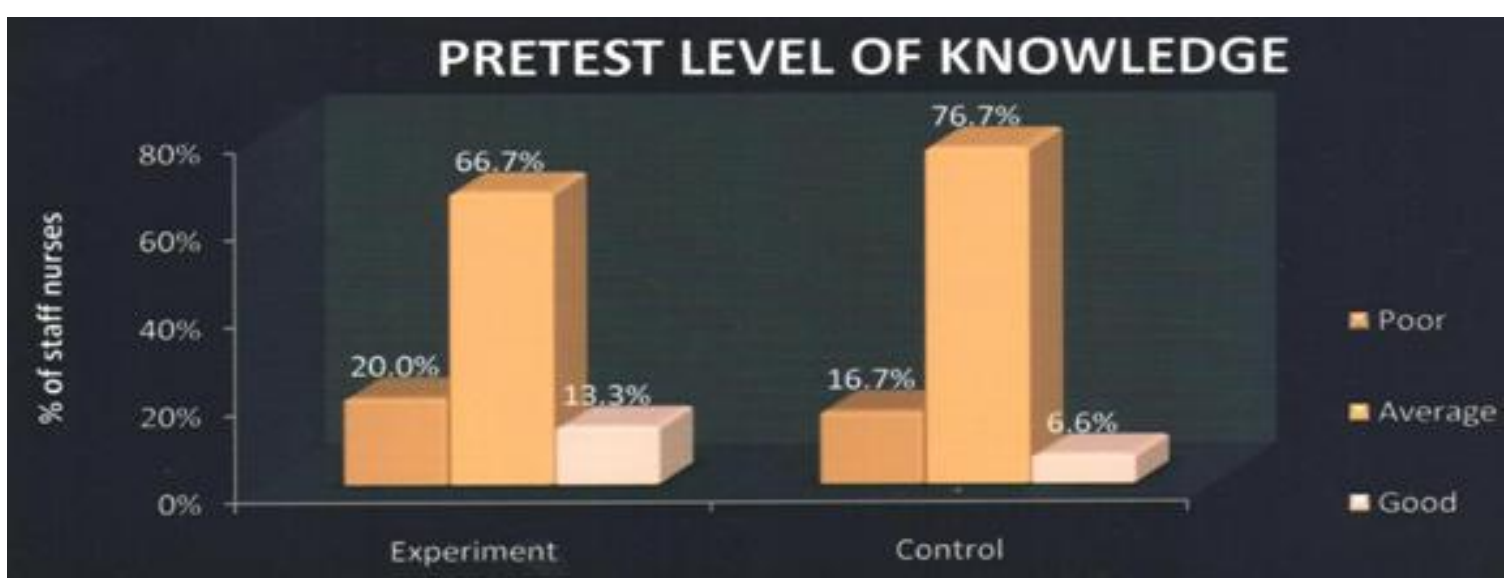

Figure 2.1: Multiple bar showing pretest level of knowledge of experimental and control group

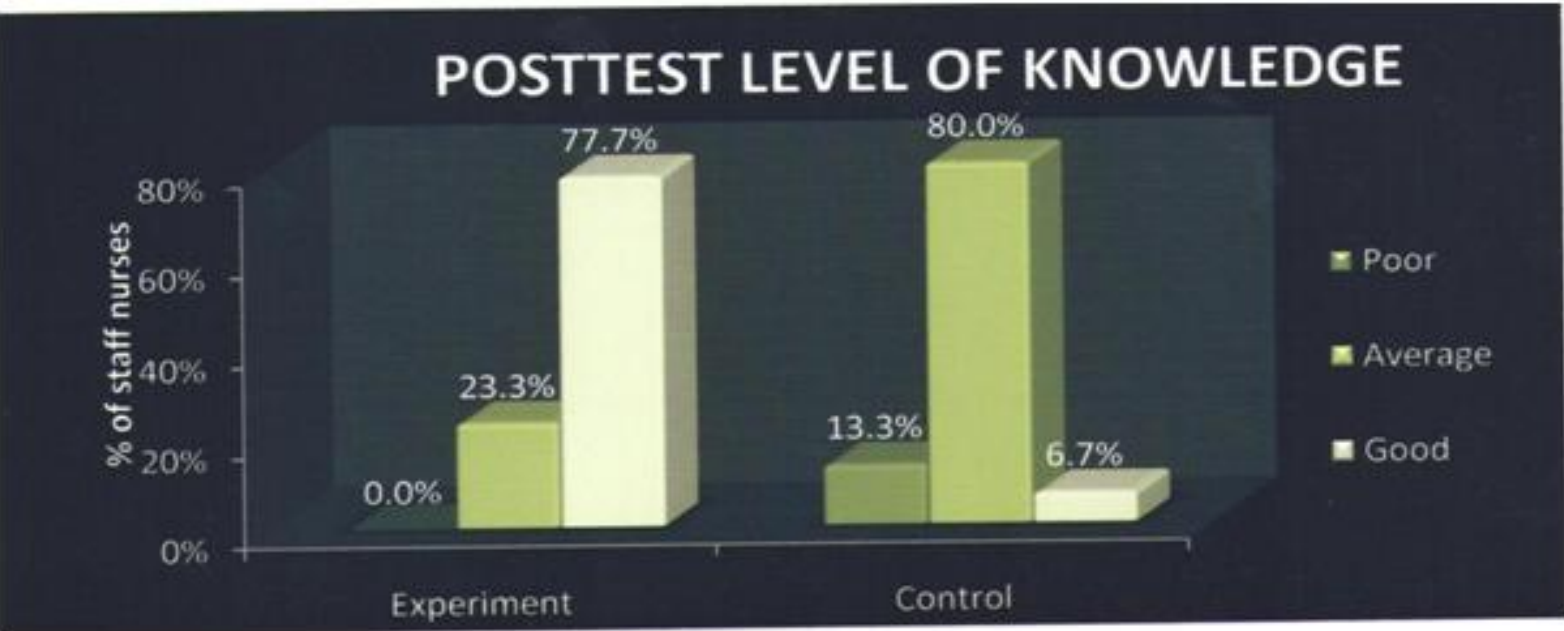

Figure 2.1: Multiple bar diagram showing post test level of knowledge of experimental and control group

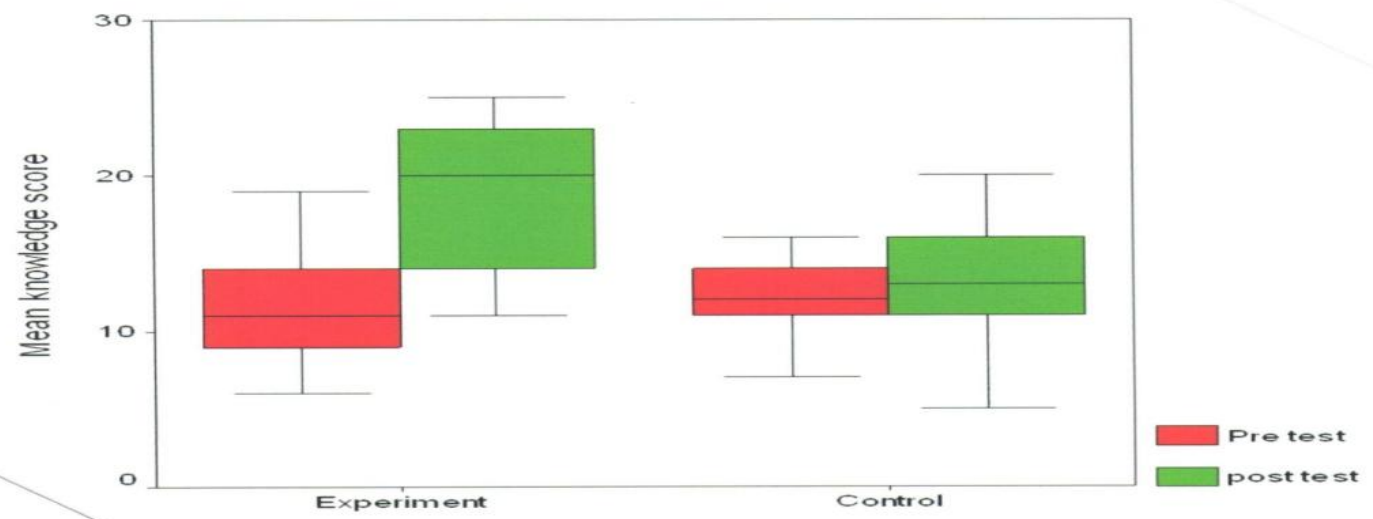

Figure 2: Box plot compares pretest and post test knowledge score between experiment and control group

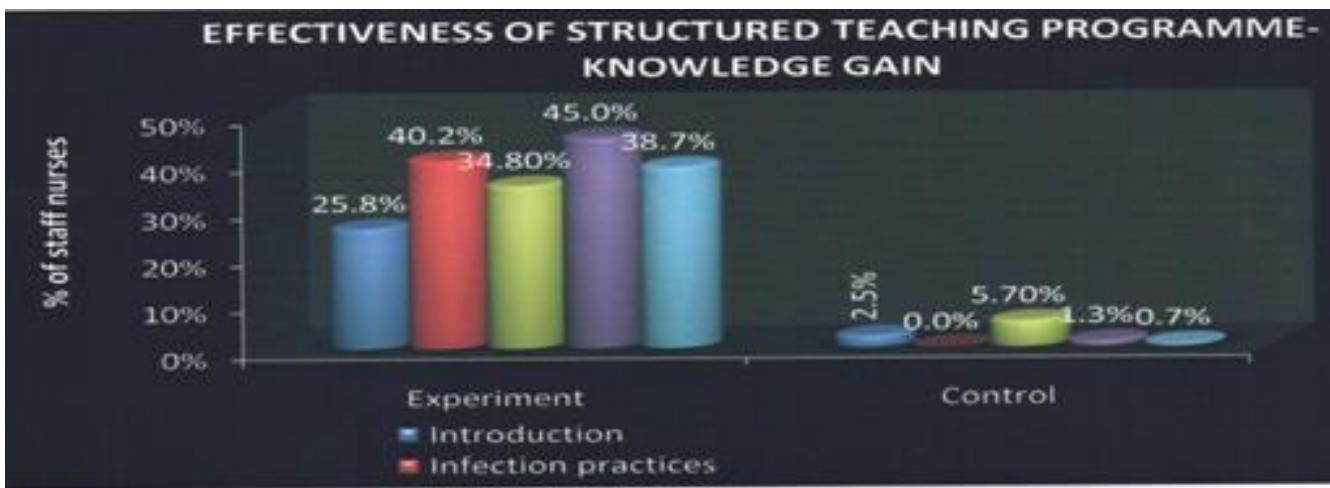

Figure 3.1: Multiple bar graph showing effectiveness of structured teaching programme- knowledge gain.

Volume 5 Issue 2, February 2016

www.ijsr.net 


\section{International Journal of Science and Research (IJSR) ISSN (Online): 2319-7064 \\ Index Copernicus Value (2013): 6.14 | Impact Factor (2014): 5.611}

Table 1: shows the demographic information of staff nurses those who are participated for the following study.

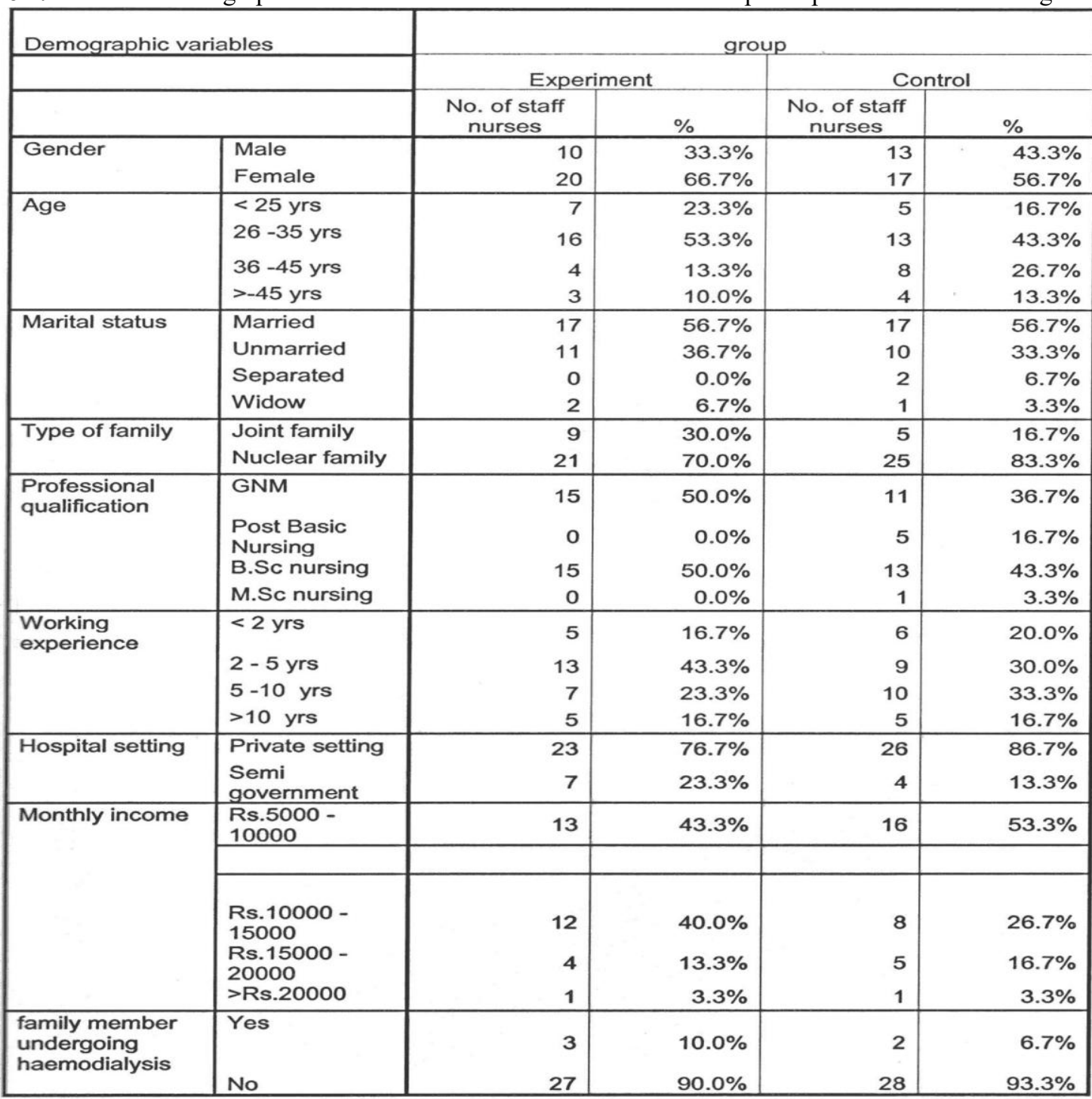

Table 1.2: Shows the comparison of staff nurses knowledge before and after the administration of STP.

\begin{tabular}{|c|c|c|c|c|c|}
\hline \multirow[t]{2}{*}{ Knowledge } & \multicolumn{2}{|c|}{ Pretest } & \multicolumn{2}{|c|}{ Posttest } & \multirow{2}{*}{$\begin{array}{l}\text { Student's paired } \\
\text { t-test }\end{array}$} \\
\hline & Mean & SD & Mean & SD & \\
\hline Introduction & 2.40 & 0.77 & 3.43 & 0.63 & $\begin{array}{c}t=5.86 \mathrm{P}=0.001 \\
* * *\end{array}$ \\
\hline Infection practices & 3.07 & 1.55 & 5.89 & 1.41 & $\mathrm{t}=6.73 \mathrm{P}=0.001$ \\
\hline $\begin{array}{l}\text { Equipment cleaning and } \\
\text { Disinfection }\end{array}$ & 3.20 & 1.45 & 4.94 & 1.89 & $t=5.73 \quad P=0.001^{* * *}$ \\
\hline $\begin{array}{l}\text { Exterior cleaning and Disinfection } \\
\text { of hemodialysis machine }\end{array}$ & 1.53 & 1.11 & 3.33 & 1.92 & $t=7.04 \mathrm{P}=0.001^{* * * *}$ \\
\hline Patient precaution and screening & 1.27 & 0.74 & 2.43 & 1.14 & $t=7.01 \quad P=0.001^{* * * *}$ \\
\hline Ov & 11.47 & 3.55 & 20.02 & 5.83 & $\begin{array}{c}t=19.69 \\
P=0.001 * * *\end{array}$ \\
\hline
\end{tabular}

Volume 5 Issue 2, February 2016 


\section{International Journal of Science and Research (IJSR) \\ ISSN (Online): 2319-7064}

Index Copernicus Value (2013): 6.14 | Impact Factor (2014): 5.611

Table 1.3 shows- Within group comparison using student"s paired t-test in pre test there is no difference between experiment and control group

\begin{tabular}{|c|c|c|c|c|c|}
\hline & \multicolumn{4}{|c|}{ Group } & \multirow[b]{3}{*}{ unpaired t-test* } \\
\hline & \multicolumn{2}{|c|}{ Experiment } & \multicolumn{2}{|c|}{ Control } & \\
\hline & Mean & SD & Mean & SD & \\
\hline Pretest & 11.47 & 3.55 & 11.87 & 2.57 & $\begin{array}{r}t=0.50 \quad P=0.61 \\
d f=58\end{array}$ \\
\hline Posttest & 20.02 & 5.83 & 12.37 & 3.27 & $\begin{array}{r}t=6.27 \\
P=0.001^{* * *} d f=58\end{array}$ \\
\hline \#Paired t-test & \multicolumn{2}{|c|}{$\begin{aligned} t=19.69 P & =0.001^{* * *} \\
d f & =29\end{aligned}$} & \multicolumn{2}{|c|}{$\begin{array}{c}t=0.69 P=0.51 \\
d f=29\end{array}$} & \\
\hline
\end{tabular}

* significant at $P \leq 0.05 *$ highly significant at $P \leq 0.01 *$ very high significant at $P \leq 0.001$

Table 1.4 shows the effectiveness of structured teaching program.

\begin{tabular}{|c|c|c|c|c|}
\hline & $\begin{array}{l}\text { knowledge } \\
\text { assessment }\end{array}$ & $\begin{array}{l}\% \text { of Pretest } \\
\text { knowledge }\end{array}$ & $\begin{array}{l}\% \text { of Posttest } \\
\text { knowledge }\end{array}$ & $\begin{array}{l}\% \text { of } \\
\text { knowledge gain }\end{array}$ \\
\hline \multirow{6}{*}{$\begin{array}{l}\text { Experimental } \\
\text { group }\end{array}$} & Introduction & $60.0 \%$ & $85.8 \%$ & $25.80 \%$ \\
\hline & Infection practices & $43.9 \%$ & $84.1 \%$ & $40.20 \%$ \\
\hline & $\begin{array}{l}\text { Equipment } \\
\text { cleaning and } \\
\text { Disinfection }\end{array}$ & $47.5 \%$ & $82.3 \%$ & $34.80 \%$ \\
\hline & $\begin{array}{l}\text { Exterior cleaning } \\
\text { and Disinfection of } \\
\text { hemodialysis } \\
\text { machine }\end{array}$ & $38.3 \%$ & $83.3 \%$ & $45.00 \%$ \\
\hline & $\begin{array}{l}\text { Patient precaution } \\
\text { and screening }\end{array}$ & $42.3 \%$ & $81.0 \%$ & $38.70 \%$ \\
\hline & OVERALL & $47.8 \%$ & $83.4 \%$ & $35.60 \%$ \\
\hline \multirow[t]{6}{*}{ Control group } & Introduction & $60.8 \%$ & $63.3 \%$ & $2.50 \%$ \\
\hline & Infection practices & $49.6 \%$ & $49.6 \%$ & $0.00 \%$ \\
\hline & $\begin{array}{l}\text { Equipment } \\
\text { cleaning and } \\
\text { Disinfection }\end{array}$ & $50.5 \%$ & $56.2 \%$ & $5.70 \%$ \\
\hline & $\begin{array}{l}\text { Exterior cleaning } \\
\text { and Disinfection of } \\
\text { hemodialysis } \\
\text { machine }\end{array}$ & $42.5 \%$ & $43.8 \%$ & $1.30 \%$ \\
\hline & $\begin{array}{l}\text { Patient precaution } \\
\text { and screening }\end{array}$ & $41.0 \%$ & $41.7 \%$ & $0.70 \%$ \\
\hline & OVERALL & $49.5 \%$ & $51.5 \%$ & $2.00 \%$ \\
\hline
\end{tabular}

Volume 5 Issue 2, February 2016 


\section{International Journal of Science and Research (IJSR) \\ ISSN (Online): 2319-7064 \\ Index Copernicus Value (2013): 6.14 | Impact Factor (2014): 5.611}

Table 1.5 shows the association between pretest level of knowledge and their demographic variables.

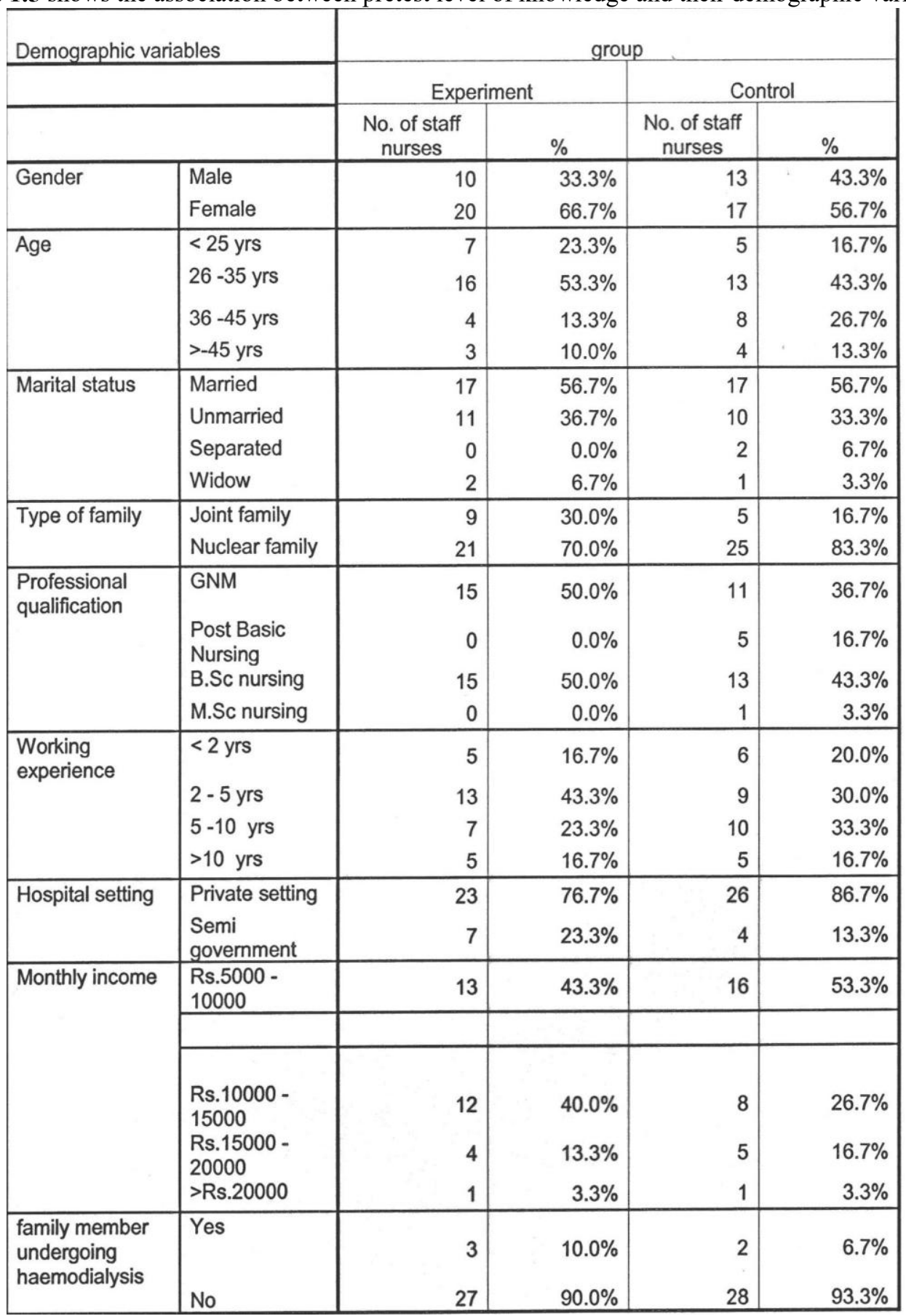

\section{Discussion}

This study discusses the major findings of the study. Structured teaching is an effective teaching method and should be encouraged. The present study was conducted to evaluate the effectiveness of structured teaching program on knowledge regarding prevention of infection among the nurses working in haemodialysis unit in selected hospital in Chhattisgarh.

In order to achieve the objective of the study, a quasi experimental design with experimental approach was adopted. Non probability purposive sampling was adopted . This subjects were divided as 30 in experimental group and 30 in control group and the data was collected before and after the administration of structured teaching program in experimental group and in control before and after without the administration of structure teaching program using structured questionnaire.

The data was collected and organized into five section. (A) Frequency and percentage distribution of the demographic variables. (B) Assess the pre test knowledge of the people in experimental and control group. (C) Assess the effectiveness of structured teaching programme. (D) Comparison of pre teat and post test scores to determine the effective of structure teaching program. (E) Association of selected demographic variables with the knowledge of nurses. The present study enabled the nurses to gain knowledge in the new protocols related to infection prevention in hemodialysis unit. The finding of study has implications for 
nursing education, nursing practice, nursing administration and nursing research.

\section{References}

[1] Paul Challinor, John Sedgewick etal (1998) "Principles and Practice of Renal Nursing" Stanley thrones publishers Pp no 185-188

[2] John T. Daugirdas, Peter Gerard Blake etal (2007) "Handbook of dialysis" $4^{\text {th }}$ edition Lippincott Williams \& Wilkins publishers Pp no 542-548.

[3] William L. Henrich (2009) "Principles and practice of dialysis" Lippincott Williams \&Wilkins publications Ppno:85-97.

[4] Guide to elimination of infection in hemodialysis unit (2010) report by "Association of professionals in Infection control".

[5] Arthur Greenberg and Alfred K.Cheung (2005) “ Primer on Kidney diseases" 4 th edition Elsevier Health Sciences publishers Pp no: 331-337.

[6] http://www.gfmer.ch/endo/fellows10/pdf/Infectioncontr ol Strategies.

[7] Jacquelyn H.Flaskerad \&Janet M.Serers, "The nursing clinics of North America Journal" vol 22, June 2002.

[8] Arking \& Barbara J.Mcarthur (2005). Strategiesto decrease infection in hemodialysis unit in "British Asian dialysis Patient Journal, Hospital Infection.” 1991 Dec: 19(4):249-55

[9] Marguerite Jackson "Infections A major issue in dialysis settings, Minerva Urol Nefrol Journal. 2005, Sep: 57 (3):199-209

[10] Jane Seden (2002)et al; A multicentre survey of the practice of hand hygiene in hemodialysis units: factors affecting compliance. Nephro Dialysis transplant Journal, 2004 June; 20 (6): 1164-71.

[11] Ghazi, Saleh, Ghazi and Badadweh (2008) An overview for the cause of infection in hemodialysis setting in Infection Dis Clin North AM.2008 Sep; 15(3):731-42, VII.

[12] www.journalagent.com

[13] Jeremy Levy etal (2005) "Oxford Handbook of Dialysis" $5^{\text {th }}$ edition oxford university press Pp no $345-$ 355 